\title{
Varioloid A, a new indolyl-6,10b-dihydro-5aH-[1]benzo- furo[2,3-b]indole derivative from the marine alga-derived endophytic fungus Paecilomyces variotii EN-291
}

\author{
Peng Zhang ${ }^{1,2}$, Xiao-Ming $\mathrm{Li}^{1}$, Xin-Xin Mao ${ }^{2}$, Attila Mándi $^{3}$, Tibor Kurtán ${ }^{* 3}$ \\ and Bin-Gui Wang ${ }^{* 1}$
}

\author{
Full Research Paper \\ Address: \\ ${ }^{1}$ Laboratory of Marine Biology and Biotechnology, Qingdao National \\ Laboratory for Marine Science and Technology, Key Laboratory of \\ Experimental Marine Biology, Institute of Oceanology, Chinese \\ Academy of Sciences, Nanhai Road 7, Qingdao 266071, China, Fax: \\ +86 $53282880645,{ }^{2}$ Tobacco Research Institute of Chinese Academy \\ of Agricultural Sciences, Qingdao 266101, China and ${ }^{3}$ Department of \\ Organic Chemistry, University of Debrecen, P. O. Box 400, 4002 \\ Debrecen, Hungary, Fax: +36 52 512-744 \\ Email: \\ Tibor Kurtán* - kurtan.tibor@science.unideb.hu; Bin-Gui Wang* - \\ wangbg@ms.qdio.ac.cn \\ * Corresponding author \\ Keywords: \\ bisindolyl benzenoid derivatives; cytotoxicity; marine alga-derived \\ fungus; Paecilomyces variotii; TDDFT-ECD calculation

\begin{abstract}
Beilstein J. Org. Chem. 2016, 12, 2012-2018.
\end{abstract} \\ doi:10.3762/bjoc. 12.188 \\ Received: 10 June 2016 \\ Accepted: 26 August 2016 \\ Published: 09 September 2016 \\ Associate Editor: A. Kirschning \\ (c) 2016 Zhang et al.; licensee Beilstein-Institut. \\ License and terms: see end of document.
}

\begin{abstract}
A new indolyl-6,10b-dihydro-5a $H$-[1] benzofuro[2,3-b]indole derivative, varioloid A (1), was isolated from the marine alga-derived endophytic fungus Paecilomyces variotii EN-291. Its structure was elucidated on the basis of extensive analysis of 1D and 2D NMR data and the absolute configuration was determined by time-dependent density functional theory-electronic circular dichroism (TDDFT-ECD) calculations. A similar compound, whose planar structure was previously described but the relative and absolute configurations and ${ }^{13} \mathrm{C}$ NMR data were not reported, was also identified and was tentatively named as varioloid B (2). Both compounds 1 and 2 exhibited cytotoxicity against A549, HCT116, and HepG2 cell lines, with $\mathrm{IC}_{50}$ values ranging from 2.6 to $8.2 \mu \mathrm{g} / \mathrm{mL}$.
\end{abstract}

\section{Introduction}

The filamentous fungus Paecilomyces variotii is a ubiquitous species commonly occurring in air, compost, infected humans, and various foodstuffs [1]. This fungus is well-known for its biotechnological applications and for its ability to produce en- zymes and proteins [2]. Its metabolic potential enables it to be a prolific source of bioactive secondary metabolites of diverse structures, including, for example, semiviriditoxin derivatives with antibacterial activity [3], cornexistin and hydroxycornex- 
istin with herbicidal activity [4], and paecilocins with antibacterial activity [5].

During our ongoing effort to search for structurally unique and bioactive secondary metabolites from marine fungi, especially from marine alga-derived fungi [6-8], we discovered evident DPPH (1,1-diphenyl-2-picrylhydrazyl) radical scavenging activity and diverse antimicrobial activities in the EtOAc extract from Paecilomyces variotii EN-291, an endophytic fungus isolated from the red alga Grateloupia turuturu. The investigation of the chemical constituents of this fungal strain had been performed and as a result, three new oxepine-containing alkaloids with antimicrobial activities $[9,10]$, two new butenolide derivatives with DPPH radical scavenging activity [11], and two new prenylated indole alkaloids with cytotoxic activity [12] had been isolated and identified. In an effort to isolate additional analogues that might show similar effects, a larger fermentation was undertaken. This study led to the isolation of two cyclized bisindolyl benzenoid derivatives (compounds 1 and 2) (Figure 1). The rare planar structure of compound $\mathbf{2}$ was previously reported but the full NMR data were not disclosed and the relative and absolute configuration had not been determined [13]. Herein we describe the isolation, structural elucidation including the assignment of the absolute configuration, and the cytotoxicity studies of these compounds.

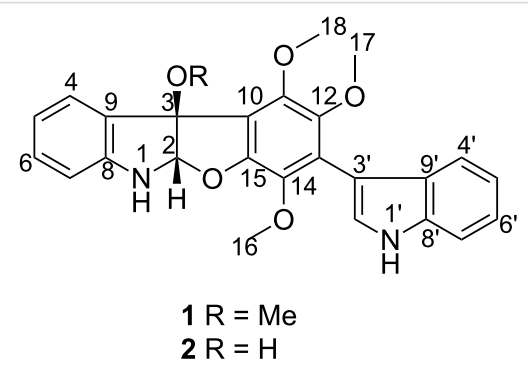

Figure 1: Structures of the isolated compounds 1 and 2.

\section{Results and Discussion}

Varioloid A (1), obtained as a light brown solid, has the molecular formula $\mathrm{C}_{26} \mathrm{H}_{24} \mathrm{~N}_{2} \mathrm{O}_{5}$ as established from a prominent pseudomolecular ion peak at $m / z 445.1766[\mathrm{M}+\mathrm{H}]^{+}$in its HRESI mass spectrum, implying 16 degrees of unsaturation. The ${ }^{1} \mathrm{H}$ NMR spectrum showed signals (Table 1) attributed to nine olefinic or aromatic protons $\left(\delta_{\mathrm{H}} 6.70-7.78\right)$, four methoxy groups $\left(\delta_{\mathrm{H}} 3.53, \mathrm{H}_{3}-16 ; 3.38, \mathrm{H}_{3}-17 ; 4.10, \mathrm{H}_{3}-18 ; 3.35\right.$, 3 -OMe), one broad indolic $\mathrm{NH}$ singlet $\left(\delta_{\mathrm{H}} 8.36,1\right.$ '-NH), and one isolated $\mathrm{sp}^{3}$-methine proton $\left(\delta_{\mathrm{H}} 6.42, \mathrm{H}-2\right)$, which were unambiguously designated by the HSQC experiment.

A comprehensive analysis of the COSY spectrum (Figure 2) revealed the existence of two 1,2-disubstituted benzenoid rings (sequential COSY correlations from $\mathrm{H}-4$ to $\mathrm{H}-7$ and from $\mathrm{H}-4$ ' to $\mathrm{H}-7^{\prime}$ '). $\mathrm{HMBC}$ correlations from the hetero-substituted methine $\mathrm{H}-2$ to $\mathrm{C}-3, \mathrm{C}-8$, and $\mathrm{C}-9$, from $\mathrm{H}-4$ to $\mathrm{C}-3$ and $\mathrm{C}-8$, and from the 3-OMe to $\mathrm{C}-3$ were instrumental in construction of the 3-methoxyindoline moiety, while additional $\mathrm{HMBCs}$ from 1'-NH to C-3' and C-9', from $\mathrm{H}-2$ ' to $\mathrm{C}-13$, and from $\mathrm{H}-4$ ' to $\mathrm{C}-3$ ' enabled extension of the partial structure to 3-indolyl group. These units accounted for six quaternary aromatic carbons and three methoxy groups, requiring the presence of a hexasubstituted benzene ring bearing three methoxy groups and the two indolyl subunits as substituents. Each methoxy signal showed an HMBC correlation to its corresponding oxygenated aromatic carbon. HMBC correlation from $\mathrm{H}-2$ to $\mathrm{C}-15$ indicated the presence of an ether bond between $\mathrm{C}-2$ and $\mathrm{C}-15$. Thus, the planar structure of compound $\mathbf{1}$ was elucidated as shown in Figure 1.

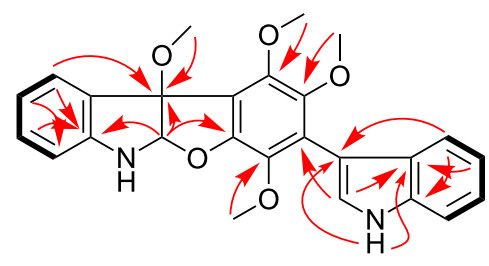

Figure 2: Key HMBC (arrows) and COSY (bond lines) correlations of compound 1.

The relative configuration of $\mathbf{1}$ was elucidated by the NOESY spectrum. Clear NOE correlation between H-2 and 3-OMe led to recognition that these protons adopt cis orientation. In order to elucidate the absolute configuration of $\mathbf{1}$, solution TDDFTECD protocol $[14,15]$ was carried out on the arbitrarily chosen $(2 R, 3 R)$ enantiomer.

The preliminary conformational search at MMFF (Merck Molecular Force Field) level resulted in 55 conformers within a $21 \mathrm{~kJ} / \mathrm{mol}$ energy window. These conformers were reoptimized at two different DFT levels, namely B3LYP/6-31G(d) in vacuo and B97D/TZVP [16,17] with a Polarizable Continuum Model (PCM) for MeCN [18]. The B3LYP optimization yielded 10 low-energy conformers above $2 \%$ Boltzmann population, while the number of low-energy conformers was 14 at the applied B97D level (Figure 3).

The conformers differed in the orientation of the methoxy groups and the value of the $\omega_{\mathrm{C} 12-\mathrm{C} 13-\mathrm{C} 3}{ }^{-} \mathrm{C} 9$, biaryl torsional angle resulting in different orientations of the $\mathrm{C}-13$ indol and dihydro-5a $H$-[1]benzofuro [2,3- $b]$ indole moieties. The different biaryl torsional angles produced markedly different computed ECD spectra for the conformers having $M$ and $P$ helicity such as the two lowest-energy computed B3LYP/6-31G(d) 
Table 1: ${ }^{1} \mathrm{H}$ and ${ }^{13} \mathrm{C}$ NMR data of compounds 1 and 2 (at $500 \mathrm{MHz}$ for ${ }^{1} \mathrm{H}$ and $125 \mathrm{MHz}$ for ${ }^{13} \mathrm{C}$, measured in $\mathrm{CDCl}_{3}$ ).

1

\begin{tabular}{|c|c|c|c|c|c|}
\hline \multirow[b]{2}{*}{ Position } & & \multirow[b]{2}{*}{ Position } & \\
\hline & $\delta_{C}$ & $\delta_{\mathrm{H}}(J$ in $\mathrm{Hz})$ & & $\delta_{C}$ & $\delta_{H}(J$ in $H z)$ \\
\hline 2 & 100.3, CH & $6.42, \mathrm{~s}$ & 2 & 104.9, CH & $6.22, \mathrm{~s}$ \\
\hline 3 & $96.1, \mathrm{C}$ & - & 3 & $90.2, \mathrm{C}$ & - \\
\hline 3-OMe & $52.1, \mathrm{CH}_{3}$ & $3.35, \mathrm{~s}$ & $3-\mathrm{OH}$ & - & $4.98, \mathrm{~s}$ \\
\hline 4 & 126.0, $\mathrm{CH}$ & $7.78, \mathrm{~d}(7.3)$ & 4 & 124.8, CH & $7.72, \mathrm{~d}(7.5)$ \\
\hline 5 & 119.8, CH & $6.90, \mathrm{t}(7.3)$ & 5 & 119.7, CH & $6.83, \mathrm{t}(7.5)$ \\
\hline 6 & $129.8, \mathrm{CH}$ & $7.19, \mathrm{t}(7.3)$ & 6 & 130.0, CH & 7.14, dd $(7.5,7.9)$ \\
\hline 7 & 109.5, CH & $6.70, \mathrm{~d}(7.3)$ & 7 & 109.8, CH & $6.66, \mathrm{~d}(7.9)$ \\
\hline 8 & 149.1, C & - & 8 & 148.6, C & - \\
\hline 9 & 127.2, C & - & 9 & 129.7, C & - \\
\hline 10 & $118.9, \mathrm{C}$ & - & 10 & 120.9 & - \\
\hline 11 & 146.0, C & - & 11 & $145.4, \mathrm{C}$ & - \\
\hline 12 & 145.7, C & - & 12 & $145.4, \mathrm{C}$ & - \\
\hline 13 & 124.6, C & - & 13 & $124.4, \mathrm{C}$ & - \\
\hline 14 & $138.4, \mathrm{C}$ & - & 14 & 138.3, C & - \\
\hline 15 & 148.6, C & - & 15 & 148.1, C & - \\
\hline 16 & $60.3, \mathrm{CH}_{3}$ & $3.53, \mathrm{~s}$ & 16 & $60.2, \mathrm{CH}_{3}$ & $3.48, \mathrm{~s}$ \\
\hline 17 & $60.5, \mathrm{CH}_{3}$ & $3.38, \mathrm{~s}$ & 17 & $60.5, \mathrm{CH}_{3}$ & $3.31, \mathrm{~s}$ \\
\hline 18 & $61.0, \mathrm{CH}_{3}$ & $4.10, \mathrm{~s}$ & 18 & 61.3, $\mathrm{CH}_{3}$ & $4.09, \mathrm{~s}$ \\
\hline $1 '-\mathrm{NH}$ & - & 8.36 , br s & 1'-NH & - & 8.29, br s \\
\hline $2^{\prime}$ & 124.5, $\mathrm{CH}$ & $7.32, \mathrm{~d}(2.2)$ & 2 & $124.4, \mathrm{CH}$ & $7.26, \mathrm{br} \mathrm{s}$ \\
\hline $3^{\prime}$ & 108.6, C & - & 3 & 108.6, C & - \\
\hline $4^{\prime}$ & 121.1, CH & $7.55, \mathrm{~d}(7.8)$ & 4 & 121.1, CH & $7.48, \mathrm{~d}(8.0)$ \\
\hline $5^{\prime}$ & 119.6, CH & $7.12, \mathrm{t}(7.8)$ & 5 & 119.7, CH & $7.05, \mathrm{t}(8.0)$ \\
\hline $6^{\prime}$ & 121.8, CH & $7.20, \mathrm{t}(7.8)$ & $6^{\prime}$ & 121.8, $\mathrm{CH}$ & $7.16, \mathrm{t}(8.0)$ \\
\hline 7 & $110.8, \mathrm{CH}$ & $7.41, \mathrm{t}(7.8)$ & 7 & 110.8, CH & $7.36, \mathrm{~d}(8.0)$ \\
\hline $8^{\prime}$ & 135.8, C & - & $8^{\prime}$ & $135.8, \mathrm{C}$ & - \\
\hline $9^{\prime}$ & 126.0, C & - & $9^{\prime}$ & 127.2, C & - \\
\hline
\end{tabular}

conformers (Figure 4). The two high-wavelength Cotton effects (CEs) had the same sign for conformer A and B, while the lower-wavelength $(<250 \mathrm{~nm}) \mathrm{CEs}$ were significantly different. The hindered rotation along the biaryl linkage may have implied an additional stereogenic element, which would have enabled atropodiastereomers with axial chirality.

In order to explore the possibility of axial chirality, torsional angle scans were performed on the lowest-energy $M$ (conformer A) and $P$ (conformer B) helicity gas-phase conformers or atropodiastereomers. Rotational energy barriers between the two isomers were estimated to be ca. $35-42 \mathrm{~kJ} / \mathrm{mol}$ for TS1 $\left(\omega_{\mathrm{C} 12-\mathrm{C} 13-\mathrm{C} 3^{\prime}-\mathrm{C} 9}, \approx 180^{\circ}\right)$ and $42 \mathrm{~kJ} / \mathrm{mol}$ for $\mathrm{TS} 2$ $\left(\omega_{\mathrm{C} 12-\mathrm{C} 13-\mathrm{C} 3^{\prime}-\mathrm{C} 9}, \approx 0^{\circ}\right)$ from the preliminary torsional scans, indicating free rotation at room temperature (Figure 5). Transition state (TS) calculations started from the energy scans' maxima resulted in TS structures with somewhat higher energies than those estimated previously $[\mathrm{TS} 1=45.3$ (46.7 with
ZPVE correction) $\mathrm{kJ} / \mathrm{mol}$ and TS2 $=46.5$ (48.1 with ZPVE correction) $\mathrm{kJ} / \mathrm{mol}$, which were however not large enough (< ca. $93 \mathrm{~kJ} / \mathrm{mol}$ ) to afford hindered rotation (Figure 6) at room temperature [19].

Thus the determination of the rotational energy barriers clearly showed that there is no axial chirality in $\mathbf{1}$, and equilibrating conformers with $M$ and $P$ helicity are present in solution as obtained in the conformational analysis.

The Boltzmann-weighted ECD spectra calculated for both the gas-phase and the solvent model conformers of $(2 R, 3 R)-\mathbf{1}$ at B3LYP/TZVP, BH\&HLYP/TZVP and PBE0/TZVP levels showed good mirror image agreement with the experimental spectrum (Figure 7). The two high-wavelength CEs above $250 \mathrm{~nm}$ were quite independent from the value of the biaryl torsional angle, while the CEs below $250 \mathrm{~nm}$ showed large differences in sign and shape with the different torsional angles. 


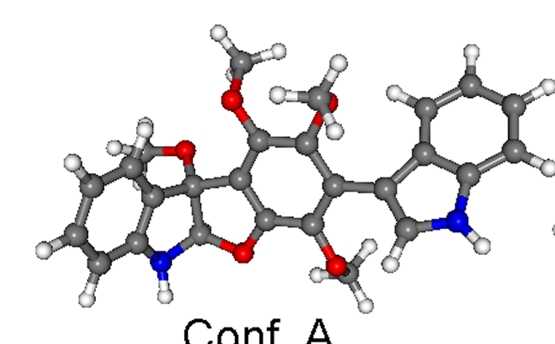

Conf. A
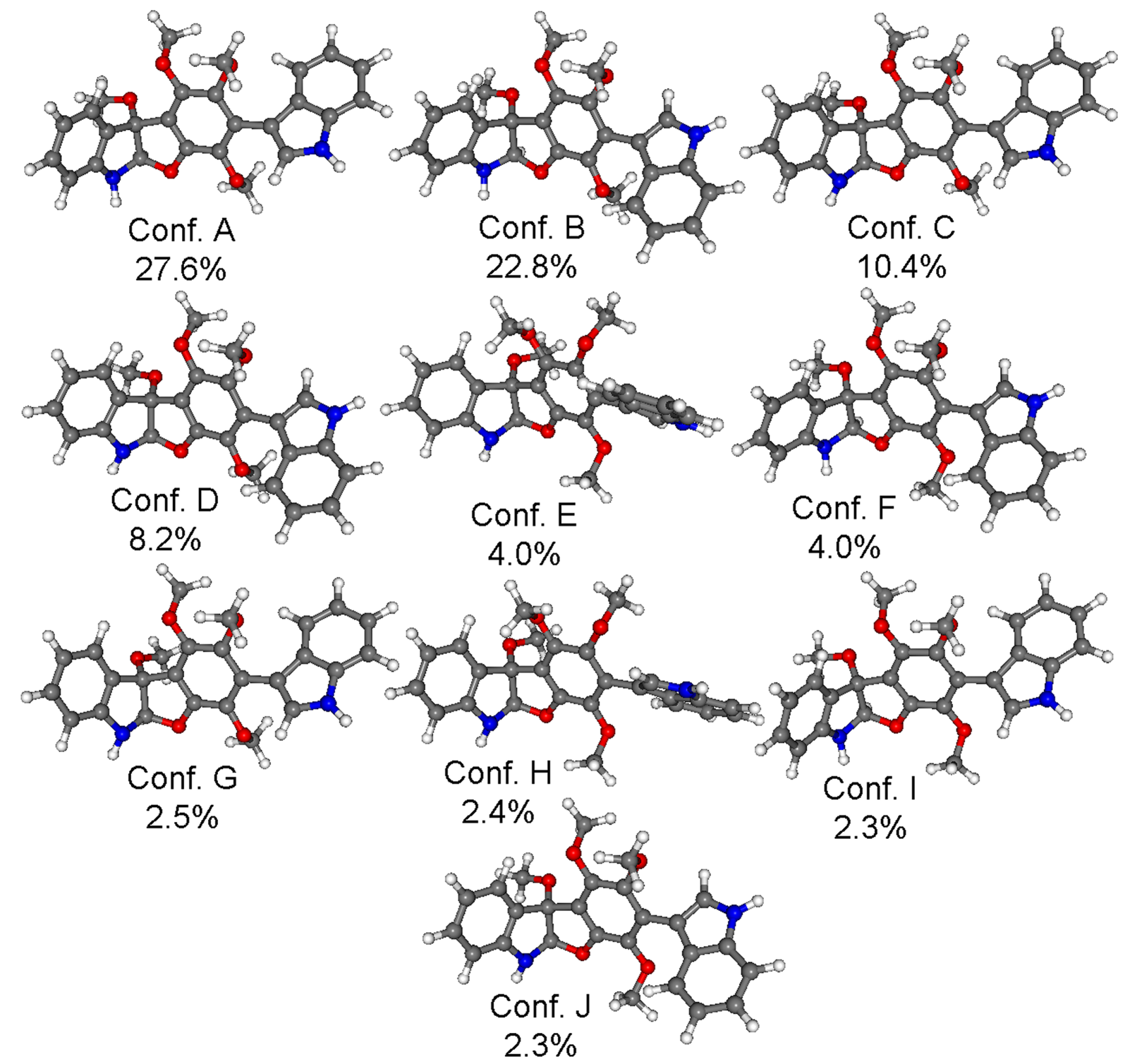

Figure 3: Structure and population of the low-energy B3LYP/6-31G(d) conformers $(>2 \%)$ of $(2 R, 3 R)-1$.

The good mirror image agreement of the experimental and computed ECD curves allowed the unambiguous assignment of the absolute configuration of $\mathbf{1}$ as $(2 S, 3 S)$, as well as the estimation of the ratio of the $P$ and $M$ helicity conformers in solution.

Compound $\mathbf{2}$ was also obtained as a light brown solid and it was identified as the 3-hydroxy derivative of $\mathbf{1}$, the planar structure of which was already reported [13]. However, the relative and absolute configurations and the full NMR data were not disclosed. The fully assigned NMR data of compound $\mathbf{2}$ was listed in Table 1 and this compound was tentatively named as varioloid B. The NOESY spectrum indicated cis relative config- uration of the two adjacent chirality centers, which was in agreement with that of $\mathbf{1}$. Given the common biosynthetic origin and congruent ECD spectrum with that of compound 1, the absolute configuration of $\mathbf{2}$ was assigned to be the same as that of 1 .

Both compounds 1 and $\mathbf{2}$ were evaluated for their cytotoxic activity using a panel of three tumor cell lines, A549 (human lung adenocarcinoma cells), HCT116 (human colon carcinoma cells), and HepG2 (human hepatoma cells). Both compounds exhibited relevant cytotoxicity. Compound 1 showed potent cytotoxicity against A549, HCT116, and HepG2 cell lines, with 


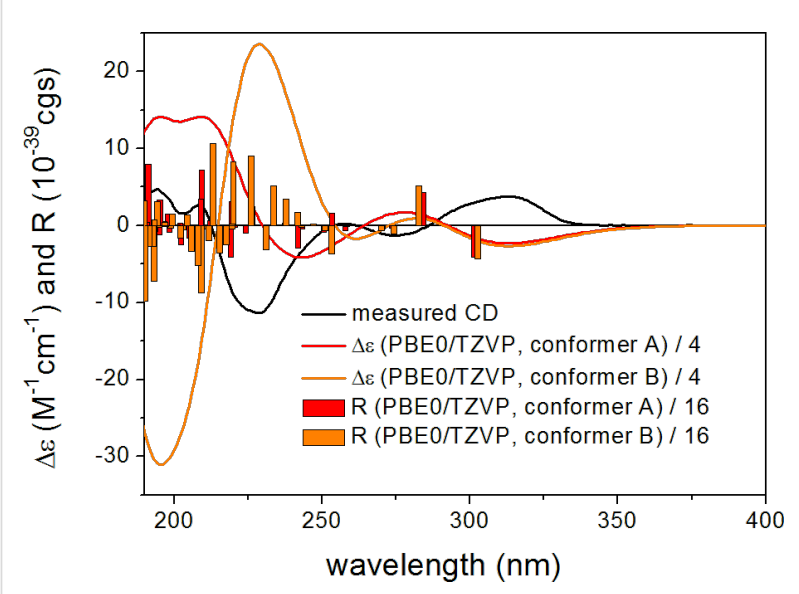

Figure 4: Experimental ECD spectrum of 1 in MeCN compared with the computed PBE0/TZVP spectra of the lowest-energy $M$

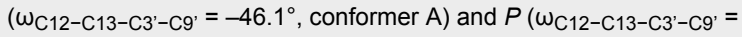
$133.4^{\circ}$, conformer $B$ ) helicity B3LYP/6-31G(d) conformers of $(2 R, 3 R)-1$. Bars represent the rotational strength values of the two conformers.

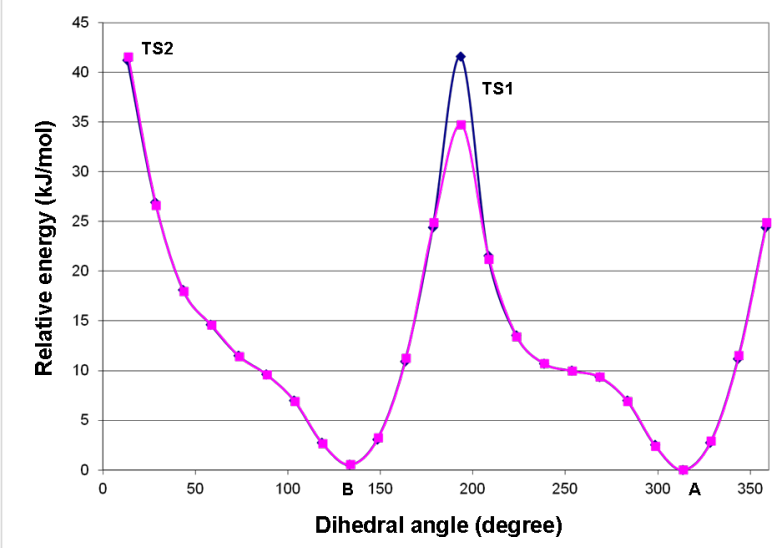

Figure 5: Torsional angle scans for estimating the rotational energy barrier around the $\mathrm{C} 13-\mathrm{C} 3$ ' bond ( $\omega_{\mathrm{C} 12}-\mathrm{C}_{13}-\mathrm{C} 3$ '- $\mathrm{C}$ ' torsional angle) of $(2 R, 3 R)-1$. The scans were started from the lowest-energy in vacuo conformers with $M$ and $P$ helicity (conformer $A$ and $\mathrm{B}$, respectively). The relative energy $(\mathrm{kJ} / \mathrm{mol})$ is plotted as the function of the $\omega_{\mathrm{C} 12-\mathrm{C} 13-\mathrm{C} 3}$ - $\mathrm{C} 9$ torsional angle. TS1 and TS2 denote the two transition states for the inversion of the helicity.

$\mathrm{IC}_{50}$ values of $3.5,6.4$, and $2.5 \mu \mathrm{g} / \mathrm{mL}$, respectively, while compound 2 also showed considerable activities, with $\mathrm{IC}_{50}$ values of $4.6,8.2$, and $6.6 \mu \mathrm{g} / \mathrm{mL}$, respectively.

\section{Conclusion}

The filamentous fungus Paecilomyces variotii continues to be a prolific source of bioactive secondary metabolites with diverse structures. In this paper, two indolyl-6,10b-dihydro-5a $H$ [1]benzofuro[2,3- $b$ ] indole derivatives, varioloids A (1) and B (2), were isolated from the marine alga-derived endophytic
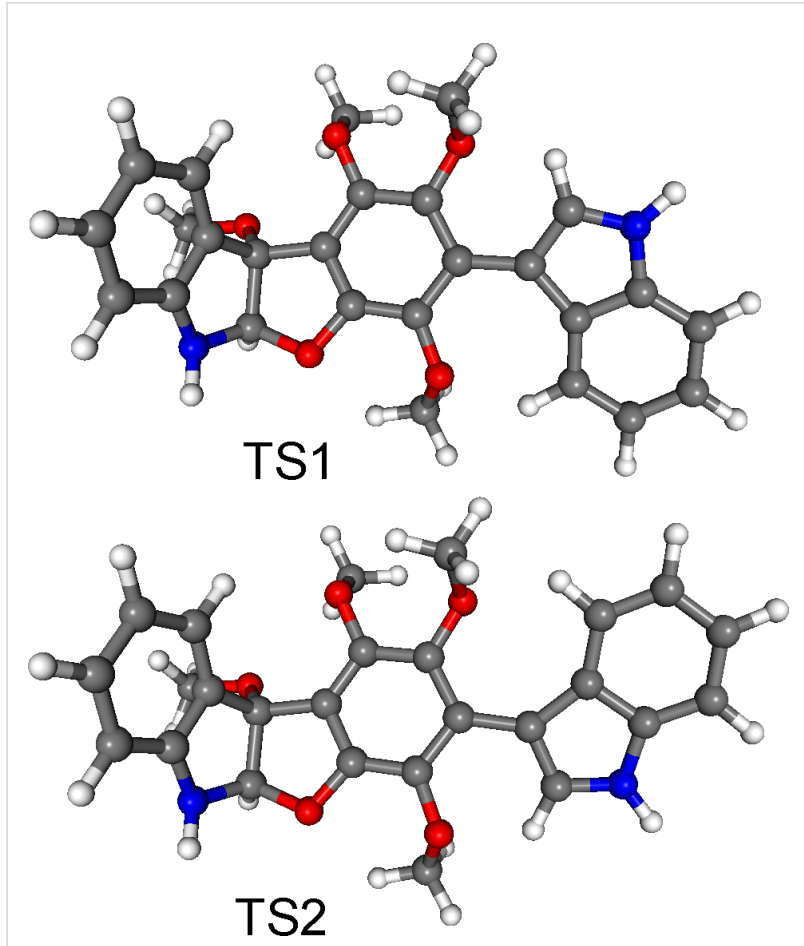

Figure 6: Transition states for the inversion of the helicity [TS1

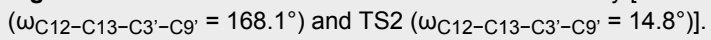

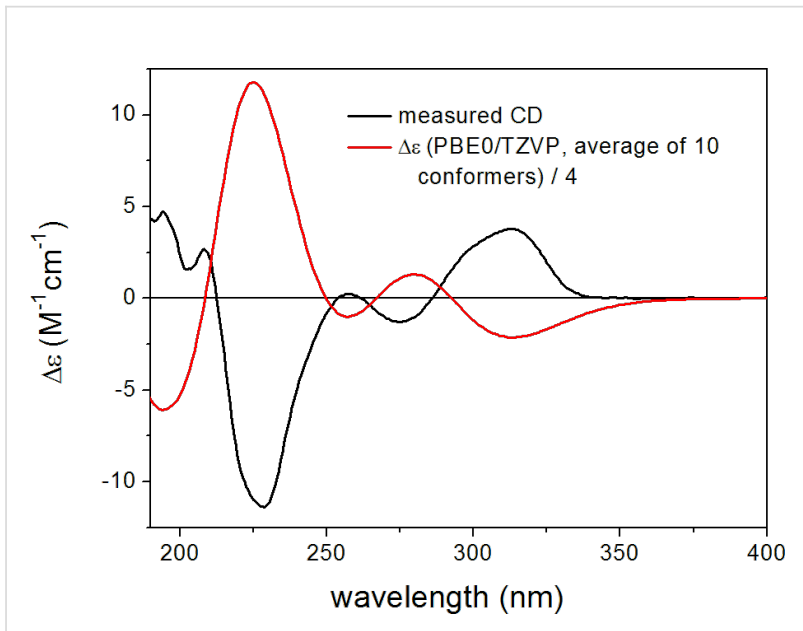

Figure 7: Experimental ECD spectrum of 1 in MeCN compared with the Boltzmann-weighted PBE0/TZVP ECD spectrum of $(2 R, 3 R)-1$ computed for the B3LYP/6-31G(d) conformers.

fungus Paecilomyces variotii EN-291. The condensed heterocyclic system in compounds $\mathbf{1}$ and $\mathbf{2}$ is quite rare among natural products. The absolute configuration of $\mathbf{1}$ was confirmed to be $(2 S, 3 S)$ by conformational analysis and TDDFT-ECD calculations. In the cytotoxicity assay, both compounds exhibited remarkable cytotoxicity. Compound 1 showed potent cytotoxicity against A549, HCT116, and HepG2 cell lines, with $\mathrm{IC}_{50}$ 
values of $3.5,6.4$, and $2.5 \mu \mathrm{g} / \mathrm{mL}$, respectively, while compound 2 also showed considerable activities, with $\mathrm{IC}_{50}$ values of $4.6,8.2$, and $6.6 \mu \mathrm{g} / \mathrm{mL}$, respectively.

\section{Experimental}

General experimental procedures: Optical rotations were measured with an Optical Activity AA-55 polarimeter. UV spectra were measured by a Lengguang Gold S54 photometer. ECD data were collected using JASCO J-715 or J-810 spectropolarimeters. NMR data were recorded on a Bruker Avance $500 \mathrm{MHz}$ spectrometer with TMS as internal standard. Low and high resolution ESI-mass spectra were recorded on a VG Autospec 3000 spectrometer. HPLC analyses were carried out on a Dionex HPLC system (P680 HPLC pump, UVD 340U UV-visible detector) using a C18 column $(5 \mu \mathrm{m}, 8.0 \mathrm{~mm}$ i.d. $\times$ $250 \mathrm{~mm}$ ). Commercial silica gel (100-200 mesh and 200-300 mesh) for column chromatography were purchased from Qingdao Haiyang Chemical Group Corporation. RP-18 reversed-phase silica gel $(40-63 \mu \mathrm{m})$ and Sephadex LH-20 were purchased from the Merck Corporation.

Fungal material: The isolation and identification of the fungus P. variotii EN-291 have been described previously [9].

Fermentation, extraction and isolation: The fungus was statically cultivated in a $1000 \mathrm{~mL}$ Erlenmeyer flask containing $300 \mathrm{~mL}$ of the PDB medium (potato dextrose broth: $2 \%$ mannitol, $1 \%$ glucose, $0.3 \%$ peptone, $0.5 \%$ yeast extract, and $300 \mathrm{~mL}$ of seawater, 60 flasks) for 30 days at room temperature. The fermented substrate $(18 \mathrm{~L})$ was extracted repeatedly with EtOAc $(3 \times 15 \mathrm{~L})$ to afford a residue $(4.3 \mathrm{~g})$, which was subjected to silica gel chromatography using a VLC column with a stepwise gradient of a mixture of petroleum ether (PE)-ethyl acetate (EtOAc) (from 5:1 to 1:1), and then by $\mathrm{CHCl}_{3}-\mathrm{MeOH}$ (20:1 and 10:1) to provide 7 fractions (1-7). Fraction $3(2.0 \mathrm{~g})$, eluted with petroleum ether-EtOAc $(3: 1, \mathrm{v} / \mathrm{v})$, was purified by column chromatography (CC) (silica gel, $\mathrm{CHCl}_{3}-\mathrm{MeOH}$ gradient, from 50:1 to $10: 1)$ to obtain five subfractions (3.1-3.5). Fraction 3.3 (200 mg) was further separated by Lobar LiChroprep RP-18 from $\mathrm{MeOH}-\mathrm{H}_{2} \mathrm{O}$ 4:6 to 7:3, and finally Sephadex LH-20 (MeOH) to afford compounds $1(16.0 \mathrm{mg})$ and $2(2.2 \mathrm{mg})$.

Varioloid A (1): Light brown solid; $[\alpha]_{\mathrm{D}}{ }^{25}+38$ (c 0.13 , $\mathrm{MeOH}) ; \mathrm{UV}(\mathrm{MeOH}) \lambda_{\max }(\log \varepsilon): 202$ (4.56), 221 (4.57), 289 (4.04) nm; ECD (MeCN, $\lambda[\mathrm{nm}](\Delta \varepsilon), c=1.8 \mathrm{mM}): 313$ (+3.78), 275 (-1.30), 257 (+0.23), 229 (-11.37), 208 (+2.71), $194(+4.70) ;{ }^{1} \mathrm{H} \mathrm{NMR}\left(500 \mathrm{MHz}, \mathrm{CDCl}_{3}, \delta, \mathrm{ppm}\right)$ and ${ }^{13} \mathrm{C}$ NMR $\left(125 \mathrm{MHz}, \mathrm{CDCl}_{3}, \delta, \mathrm{ppm}\right)$ data, see Table 1. HRMS-ESI $(m / z):[\mathrm{M}+\mathrm{H}]^{+}$calcd for $\mathrm{C}_{26} \mathrm{H}_{24} \mathrm{~N}_{2} \mathrm{O}_{5}, 445.1758$; found, 445.1766 .
Varioloid B (2): Light brown solid; $[\alpha]_{\mathrm{D}}{ }^{25}+36(c 0.17$, EtOH) (lit. $\left.[\alpha]_{\mathrm{D}}{ }^{18}+34.3(c 0.11, \mathrm{EtOH})\right)[13]$; UV $(\mathrm{MeOH}) \lambda_{\max }(\log$ ع): 202 (4.71), 221 (4.72), 289 (4.17) nm; ECD (MeCN, $\lambda$ [nm] $(\Delta \varepsilon), c=0.56 \mathrm{mM}): 312(+5.34), 274(-1.77), 256(+0.20), 229$ $(-11.93), 206(+4.14), 192(+3.20) ;{ }^{1} \mathrm{H}$ NMR $(500 \mathrm{MHz}$, $\left.\mathrm{CDCl}_{3}, \delta, \mathrm{ppm}\right)$ and ${ }^{13} \mathrm{C} \mathrm{NMR}\left(125 \mathrm{MHz}, \mathrm{CDCl}_{3}, \delta, \mathrm{ppm}\right)$ data, see Table 1 .

Computational methods: Mixed torsional/low-mode conformational searches were carried out by means of the Macromodel 9.9.223 software [20] using the Merck Molecular Force Field (MMFF) with an implicit solvent model for $\mathrm{CHCl}_{3}$ applying a $21 \mathrm{~kJ} / \mathrm{mol}$ energy window. Geometry reoptimizations of the resultant conformers [B3LYP/6-31G(d) level in vacuo and B97D/TZVP [16,17] with a solvent model (PCM) for $\mathrm{MeCN}]$ and TDDFT calculations were performed with Gaussian 09 [21] using various functionals (B3LYP, BH\&HLYP, PBE0) and the TZVP basis set. ECD spectra were generated as the sum of Gaussians [22] with $3000 \mathrm{~cm}^{-1}$ halfheight width (corresponding to ca. $15 \mathrm{~nm}$ at $225 \mathrm{~nm}$ ), using dipole-velocity-computed rotational strengths. Boltzmann distributions were estimated from the ZPVE-corrected B3LYP/6-31G(d) energies in the gas-phase calculations and from the B97D/TZVP energies in the PCM model ones. Torsional energy scans and TS calculations were carried out at the B3LYP/6-31G(d) level in vacuo. The MOLEKEL [23] software package was used for visualization of the results.

Cytotoxicity assay: The cytotoxic activities against A549, HCT116, and HepG2 cell lines were determined by the MTT (3-(4,5-dimethylthiazol-2-yl)-2-5-diphenyltetrazolium bromide) assay according to previously reported methods [24,25]. Briefly, the cells cited above were grown in RPMI 1640 (Sigma R6504) medium supplemented with $10 \%$ fetal calf serum (Gibco 16000-044) at $37{ }^{\circ} \mathrm{C}$ in humidified air with $5 \%$ $\mathrm{CO}_{2}$. Then the cell lines were treated with test compounds for $48 \mathrm{~h}$, and subsequently MTT solution was added. After incubation for $3 \mathrm{~h}$, the blue formazan generated was solubilized with $0.04 \mathrm{M} \mathrm{HCl}$ in isopropanol. The absorbance at $570 \mathrm{~nm}$ was read in a Synergy ELISA plate reader (Bio Tek Instruments).

\section{Supporting Information}

\section{Supporting Information File 1}

Selected 1D and 2D NMR spectra of compounds $\mathbf{1}$ and $\mathbf{2}$, and computed solvent model ECD spectrum of compound 1.

[http://www.beilstein-journals.org/bjoc/content/ supplementary/1860-5397-12-188-S1.pdf] 


\section{Acknowledgments}

Financial support from the Natural Science Foundation of China (31330009) and from the Scientific and Technological Innovation Project of Qingdao National Laboratory for Marine Science and Technology (No.2015ASKJ02) is gratefully acknowledged. T.K. and A.M. thank the Hungarian National Research Foundation (OTKA K105871) for financial support and the National Information Infrastructure Development Institute (NIIFI 10038) for CPU time.

\section{References}

1. Jamali, S.; Banihashemi, Z. Rostaniha 2011, 12, 191-192.

2. Toledo Marante, F. J.; Mioso, R.; Bermejo Barrera, J.; González, J. E. G.; Rodríguez, J. J. S.; de Laguna, I. H. B. Ann. Microbiol. (Heidelberg, Ger.) 2012, 62, 1601-1607. doi:10.1007/s13213-011-0416-1

3. Ayer, W. A.; Craw, P. A.; Nozawa, K. Can. J. Chem. 1991, 69, 189-191. doi:10.1139/v91-030

4. Fields, S. C.; Mireles-Lo, L.; Gerwick, B. C. J. Nat. Prod. 1996, 59, 698-700. doi:10.1021/np960205e

5. Liu, J.; Li, F.; Kim, E. L.; Li, J. L.; Hong, J.; Bae, K. S.; Chung, H. Y.; Kim, H. S.; Jung, J. H. J. Nat. Prod. 2011, 74, 1826-1829. doi:10.1021/np200350b

6. Du, F.-Y.; Li, X.-M.; Song, J.-Y.; Li, C.-S.; Wang, B.-G. Helv. Chim. Acta 2014, 97, 973-978. doi:10.1002/hlca.201300358

7. Li, X.; Li, X.-M.; Xu, G.-M.; Li, C.-S.; Wang, B.-G. Phytochem. Lett. 2014, 7, 120-123. doi:10.1016/j.phytol.2013.11.008

8. Zhang, P.; Li, X.-M.; Li, X.; Wang, B.-G. Phytochem. Lett. 2015, 12, 182-185. doi:10.1016/j.phytol.2015.03.017

9. Zhang, P.; Mándi, A.; Li, X.-M.; Du, F.-Y.; Wang, J.-N.; Li, X.; Kurtán, T.; Wang, B.-G. Org. Lett. 2014, 16, 4834-4837. doi:10.1021/ol502329k

10. Zhang, P.; Li, X.-M.; Wang, J.-N.; Wang, B.-G. Helv. Chim. Acta 2015, 98, 800-804. doi:10.1002/hlca.201400328

11. Zhang, P.; Li, X.-M.; Wang, J.-N.; Li, X.; Wang, B.-G. Phytochem. Lett. 2015, 11, 85-88. doi:10.1016/j.phytol.2014.11.014

12. Zhang, P.; Li, X.-M.; Wang, J.-N.; Li, X.; Wang, B.-G. Chin. Chem. Lett. 2015, 26, 313-316. doi:10.1016/j.cclet.2014.11.020

13. Arai, K.; Shimizu, S.; Yamamoto, Y. Chem. Pharm. Bull. 1981, 29, 1005-1012. doi:10.1248/cpb.29.1005

14. Mándi, A.; Mudianta, I. W.; Kurtán, T.; Garson, M. J. J. Nat. Prod. 2015, 78, 2051-2056. doi:10.1021/acs.jnatprod.5b00369

15. Tóth, L.; Fu, Y.; Zhang, H. Y.; Mándi, A.; Kövér, K. E.; Illyés, T.-Z.; Kiss-Szikszai, A.; Balogh, B.; Kurtán, T.; Antus, S.; Mátyus, P. Beilstein J. Org. Chem. 2014, 10, 2594-2602. doi:10.3762/bjoc.10.272

16. Grimme, S. J. Comput. Chem. 2006, 27, 1787-1799. doi:10.1002/jcc.20495

17. Sun, P.; Xu, D.-X.; Mándi, A.; Kurtán, T.; Li, T.-J.; Schulz, B.; Zhang, W. J. Org. Chem. 2013, 78, 7030-7047. doi:10.1021/j0400861j

18. Pescitelli, G.; Bruhn, T. Chirality 2016, 28, 466-474. doi:10.1002/chir.22600

19. Bringmann, G.; Mortimer, A. J. P.; Keller, P. A.; Gresser, M. J.; Garner, J.; Breuning, M. Angew. Chem., Int. Ed. 2005, 44, 5384-5427. doi:10.1002/anie.200462661

20. MacroModel. Schrödinger LLC, 2012. http://www.schrodinger.com/MacroModel.

21. Gaussian 09, Revision B.01; Gaussian, Inc.: Wallingford, CT, 2010.
22. Stephens, P. J.; Harada, N. Chirality 2010, 22, 229-233. doi:10.1002/chir.20733

23. Varetto, U. MOLEKEL, 5.4.; Swiss National Supercomputing Centre: Manno, Switzerland, 2009.

24. Bergeron, R. J.; Gavanaugh, P. F., Jr.; Kline, S. J.; Hughes, R. G., Jr.; Elliott, G. T.; Porter, C. W. Biochem. Biophys. Res. Commun. 1984, 121, 848-854. doi:10.1016/0006-291X(84)90755-1

25. Kikuchi, T.; Ishii, K.; Noto, T.; Takahashi, A.; Tabata, K.; Suzuki, T.; Akihisa, T. J. Nat. Prod. 2011, 74, 866-870. doi:10.1021/np100783k

\section{License and Terms}

This is an Open Access article under the terms of the Creative Commons Attribution License

(http://creativecommons.org/licenses/by/4.0), which permits unrestricted use, distribution, and reproduction in any medium, provided the original work is properly cited.

The license is subject to the Beilstein Journal of Organic Chemistry terms and conditions: (http://www.beilstein-journals.org/bjoc)

The definitive version of this article is the electronic one which can be found at: doi:10.3762/bjoc. 12.188 